Article

\title{
Do Synergies Pop up Magically in Digital Transformation-Based Retail M\&A? Valuing Synergies with Real Options Application
}

\author{
Andrejs Čirjevskis@ \\ Business Department, RISEBA University of Applied Sciences in Business, Arts, and Technology, LV-1048 Riga, \\ Latvia; andrejs.cirjevskis@riseba.lv; Tel.: +371-29558375
}

Received: 20 January 2020; Accepted: 4 March 2020; Published: 6 March 2020

\begin{abstract}
This paper aims to explore and to illustrate success factors of reciprocal synergies of digital transformation-based merger and acquisition (M\&A) deals in the grocery retail industry. The author carried out a case study on the merger of Ahold Delhaize in 2016. The paper's contribution is a conceptual model of research that helps in pre-acquisition analysis on competence-based synergies in M\&A to value strategic synergies as market value added a using real options application. By combining qualitative and quantitative research methods, the author provides empirical evidence to indicate the validity and value of the proposed research framework for both scholars and practitioners alike.
\end{abstract}

Keywords: digital transformation; merger and acquisition; synergy; real option

\section{Introduction}

The combination of tacit knowledge, as well as codified knowledge, can generate competence-based synergy through the merger and acquisition. However, to construct a holistic integrated research framework of competence-based synergies in M\&A deals is an overly complicated task. This paper aims to explore the success factors of reciprocal synergies of a digital transformation-based M\&A deal in the grocery retail industry. In the current paper, the author argues that the intersection between core competence theory [1] and real options theory enables the acquirer to elect and exercise those options that have a high probability to provide managerial synergies and expire the options that have a low probability.

Even though there are many differences between core competence theory and dynamic capability framework like the difference in the origin, in the aims, and the context of usage, there are many similarities within the two concepts. Both are "necessary for managing changes and both are created by managers [2] (p. 395)". Core competences are necessary to exploit real options and opportunities, "whereas real options are necessary to evaluate opportunities" [2].

Jahanshahi and Nawaser [2] argue that a study on a real option and dynamic capabilities as the ability to build, integrate, and reconfigure core competences to address rapidly changing environments [3] suggest future research on many open questions. "Future research can test this relationship in the project and firm-level [2] (p. 400)". What is more, Trigeorgis and Reuer [4] (p. 57) argue, "we would encourage the use of real option with a greater focus on the individual project level of analysis, ... on individual real option cases". The current paper contributes to this scientific discussion and seeks to address the research gaps.

To bridge the divide and to provide an approach to value synergies in M\&A as real options, the paper empirically illustrates a successful digital transformation-based M\&A deal in grocery retail business, namely, the Ahold-Delhaize merger in 2016 and thus, contributes to theory and practice by empirically illustrating how two theories work in the M\&A process. 
The author asks a research question: how to value strategic synergies in a digital transformationbased grocery retail M\&A deal employing real options? Having provided the answer, the paper demonstrates an application of real options valuation technique (Black-Scholes Option Pricing Model and Real Option Binominal Lattice) to quantitatively measure competence-based synergies in M\&A deals. Being at the intersection of the strategic management and corporate finance disciplines, the current research provides an integrated research framework for both scholars and practitioners alike. Therefore, having analyzed advanced managerial practice, the paper answers the question of the Strategy Practice group of the Strategic Management Society: how do digital technologies get used in strategizing?

The paper is organized as follows. The study starts with a scientific discussion on what main ideas have been proposed concerning achieving synergy in M\&A and where the current literature falls short in explaining and predicting when, what, and how much synergies occur. Then, the author introduces an integrative conceptual model of the research to explain the valuation of M\&A synergy through real options application in the context of digital transformation in the retail industry. To test and to illustrate empirically how to value of M\&A synergies using real options application in the context of digital transformation, the author selected an inductive (illustrative) case study of one of the most successful recent digital transformation-based mergers in grocery retail industry, namely, the Ahold-Delhaize merger in 2016. By combining qualitative and quantitative research methods, the author provides empirical evidence to indicate the validity and value of the proposed research framework for both scholars and practitioners alike. At the end of the paper, the author discusses empirical and theoretical findings, limitations, and future work.

\section{Key Literature Review}

\subsection{Competence-Based Synergies in MEA}

"Understanding core competences allows companies to invest in the strengths that differentiate them and set strategies that unify their entire organization [5] (p. 1)". According to Barney [6], each competence can be a source of sustained competitive advantage only if it creates value (V), is unique and rare $(\mathrm{R})$, is hard to imitate or substitute (I), and the focal company has reporting structures, formal and informal management control systems, hiring and retention policies, and compensation policies, allowing the company to organize $(\mathrm{O})$ to exploit those competences. Moreover, Barney [6] states that core competences should be analyzed using the VRIO framework in terms of their ability to produce valuable and rare synergies, and therefore bring a competitive advantage to the company.

The M\&A synergy issue touches on many key research streams in the strategy literature. For instance, it includes the ideas of the resource-based view of the firm and VRIO framework [6], the framework of recombinant innovation [7], the speed of strategic decisions [8], the real options perspective [9], and cultural factors in strategic management [10]. These research streams rely on heterogeneous sets of assumptions and have diverse theoretical origins. It is very challenging to clearly integrate a vast number of constructs from these research streams and to effectively reconcile the potential conflicts in the sets of assumptions.

Given the theoretical complexity of integrating the above ideas into one framework, it is important to clearly articulate the connections of the key constructs and the research streams that are embedded in to show the validity of adopting these constructs in the first place. This paper touches on the more specific arguments of associate research streams with further and detailed elaborations of the conceptual model for the current and future research.

A recent study of Rozen-Bakher [11] presents a research model that includes six pre-M\&A performances - the revenue and profitability of the acquirer and the target, the revenue ratio and profitability ratio- to analyze if the pre-M\&A performances could predict integration success. Homburg and Bucerius [12], King et al. [13] identified and resumed their prominent research stream in strategic management literature that the strategic fit is decisive for M\&A success. Meyer and Altenborg [14] 
argue that the strategic fit is an indicator of the synergy potential of a transaction. One more important factor is cultural incompatibility or misfit, this is one of the most cited reasons for the low success rates of M\&As [15-18]. The post-merger integration phase is often cited to be decisive for M\&A [18,19]. In the post-merger integration phase, well-established operational sequences and patterns are partially or completely changed, and throughout the new company, harmonized [18].

Thereby, acquisitions without any integration, resource redeployment, and exploitation, as well as the elimination of redundant resources, are not feasible [12,20-22]. What's more, Angwin [23] and Bauer and Matzler [24] argue that speed of integration can lead to faster exploitation of synergies and returns on investment, reduce uncertainty among employees, minimize time spent in a suboptimal condition, and takes advantage of the momentum in the direct aftermath of a deal. With respect to previous research, those papers were the first to critically examine speed, performance in $\mathrm{M} \& \mathrm{~A}$, and strategic fit; their empirical evidence didn't suggest what type of synergies collaborating companies result.

Synergies in an acquisition are a function of strategic similarity, complementarities, and transferability of core competencies in the M\&A deal. Dyer et al.'s research [25] has made a strong contribution to correlations of the type of synergy with collaboration options. "First, companies create modular synergies when they manage resources independently and pool only the results for greater profits; the synergies are modular because modularly interdependent resources generate them. Second, firms derive sequential synergies when one company completes its tasks and passes on the results to a partner to do its bit. Third, companies generate reciprocal synergies by working closely together and executing tasks through an iterative knowledge-sharing process. For companies that desire those synergies, acquisitions are better than alliances [25], (p. 5)".

Therefore, a competence-based synergy is a reciprocal synergy that is generated by compatibilities of partners' core competencies at collaborating [25]. To measure synergies quantitatively, Rabier [26] recommends estimating an operating synergy (e.g., revenue growth through new product offerings or cost savings through economies of scale) that is more likely to result in higher operating profit margin and financial synergies (e.g., diversification of cash flow streams and lowering the cost of capital). Thereby, synergies are mainly analyzed by scholars quantitatively, in terms of revenue and cost.

However, in practice, it is a much more complicated valuation because some success factors are not quantitatively measurable. The mutual trust of two partners, interpersonal relationships of middle management, absorption capacities (a desire to learn, not substitute), digital transformation effect on supply chain management of the retailers and their sales' force, as well as managerial flexibility are almost impossible to measure with operating or net profit margins. In this vein, the value of synergies of competence-based synergies in M\&A can be measured with a real options valuation technique.

To sum up the sub-chapter, managerial synergies in M\&A deals are provided by the degree of similarities, complementarity, and transferability of the dynamic capabilities of an acquirer and a target, and can be measured by real option.

\subsection{Measuring Competence-Based Synergies in MEA with a Real Option Valuation}

The incorporation of real options into the synergy valuation measures managerial flexibility arising from M\&A deals [27]. The synergies can be viewed as a real option value (market value added) that is created in a merger or an acquisition. What's more, Bruner [28] emphasized the relevance of real options for M\&A practitioners. The paper adopted recommendations of Dunis and Klein [29] (p. 8) regarding input variables for the valuation synergies as real options as follows.

The share price (So) equivalent of the option is the cumulated market value of target and acquirer or their capitalization before the merger. Data of market capitalization are usually available on https://www.reuters.com/, https://www.google.com/finance, and other available sources. The exercise price $(\mathrm{E})$ is the combined hypothetical future market value of the target and an acquirer after one year without a merger. The hypothetical future market value of the separated entities forecast can be done with multiples analyses and/or with discounted free cash flow forecasts. 
The volatility $(\sigma)$ of share price can be obtained from the V-Lab APARCH Volatility Analysis [30] or by direct observation. Duration ( $\mathrm{T}$ ) getting synergy is managerial anticipation of when competence-based synergies would be fully realized in terms of the year following completion of the merger or acquisition. The risk-free rate (rf) is a long-term government bond yield [29].

Therefore, the option of potential M\&A benefits to the shareholders is a European call option on the market value of the merged company with the expected future stand-alone market value defined as the exercise price. To model the option as an American call option with a stochastic exercise price would have been reasonable too. The call option premium as competence-based synergies results can be calculated using an Excel spreadsheet in either the European or American type of option. To conclude the theoretical part of this paper, the competence-based (reciprocal) synergy in M\&A can be measured with real option application, namely, with Black Scholes Option Pricing Model (European option) and the Binomial Option Pricing Model using real option binominal lattice (American option).

To sum up the sub-chapter, the competence-based synergies in M\&A deals can be measured by real options application using Black Scholes Option Pricing Model (BSOPM) and the Binomial Option Pricing Model (BOPM).

\section{Research Design and Methodology}

Yin defines the case study research method as "an empirical inquiry that investigates a contemporary phenomenon within its real-life context; when the boundaries between phenomenon and context are not evident; and in which multiple sources of evidence are used [31] (p. 23)". When it comes to the validity of a qualitative case study research [32], the validity refers to the extent to which the qualitative research results accurately represent the collected data (internal validity) and can be generalized or transferred to other contexts or settings (external validity). It is a major advantage of a case study research that the few chosen samples can be investigated in depth, which would not be possible with a large case sample [33].

The data analysis and interpretations were organized as two phases of the research. Within the first phase of the research, the primary data (qualitative and quantitative) were collected and analyzed, namely, semi-structured interviews with experts who were involved in this merger. The interviews were designed by both open-ended and eleven closed questions. Interview questions focused on three themes: M\&A strategies in the grocery retail business, factors of synergies creation, and the Ahold Delhaize (AD) merger's organizational issues (strategic rationales behind the merger and sources of expected synergies).

Moreover, to generalize the success factors impacting competence-based synergies creation, online survey questionnaires were sent to experts of grocery retail companies that are active in the business. The survey questions $(n=180)$ were related to respondents' experiences in M\&A strategies and synergy creation processes. The survey's analysis helped to justify critical success factors obtained from interviewed persons in earlier research.

The current case study also relied on secondary data, namely, an extensive archival search that included financial statements, annual reports, internal documents, industry publications, and CEO statements to get at a micro-level understanding, that boosts research data. The key to secondary data analysis is to apply theoretical knowledge and conceptual skills to utilize existing data to address the research questions [34]. The major advantages associated with secondary analysis are cost-effectiveness and the convenience it provides (Smith, 2008). A major disadvantage of using secondary data is that the secondary researchers did not participate in the data collection process and did not know exactly how it was conducted. However, the obvious benefits of using secondary data can be overshadowed by its limitations [34].

Original survey research rarely uses all of the data collected and this unused data can provide answers or different perspectives to other questions or issues [35]. In a time where vast amounts of data are being collected and archived by researchers all over the world, the practicality of utilizing existing data for research is becoming more prevalent $[35,36]$. Regarding the presentation of evidence, 
due to the rich amount of data that is piled up during a case study, Eisenhardt and Graebner state that there is no strict norm, as in large-scale studies, when presenting results [37].

Therefore, the second phase of the research involves a demonstration of the application to value synergy as a real option. The secondary data analysis added enough information to value a competence-based (reciprocal) synergies quantitatively as a value of European (Black- Scholes option pricing model) and American (Binomial options pricing model) options.

Practically, the conceptual model of the research (Figure 1) consists of three stages to answer the research question. In the first stage, core competencies of both companies (acquirer and target) are identified using the VRIO framework [6] and evaluated in terms of their compatibility, complementarity, and transferability for merging partners in the M\&A process to generate competence-based synergy. The identification of the type of competence-based synergies (modular, sequential, or reciprocal) with a help Dyer et al. framework is the next second stage of the research. The final third stage of research is a real options valuation application to measure a synergy (market value-added) in M\&A by real options application using BSOPM and BOPM. The conceptual model of research is presented in Figure 1.

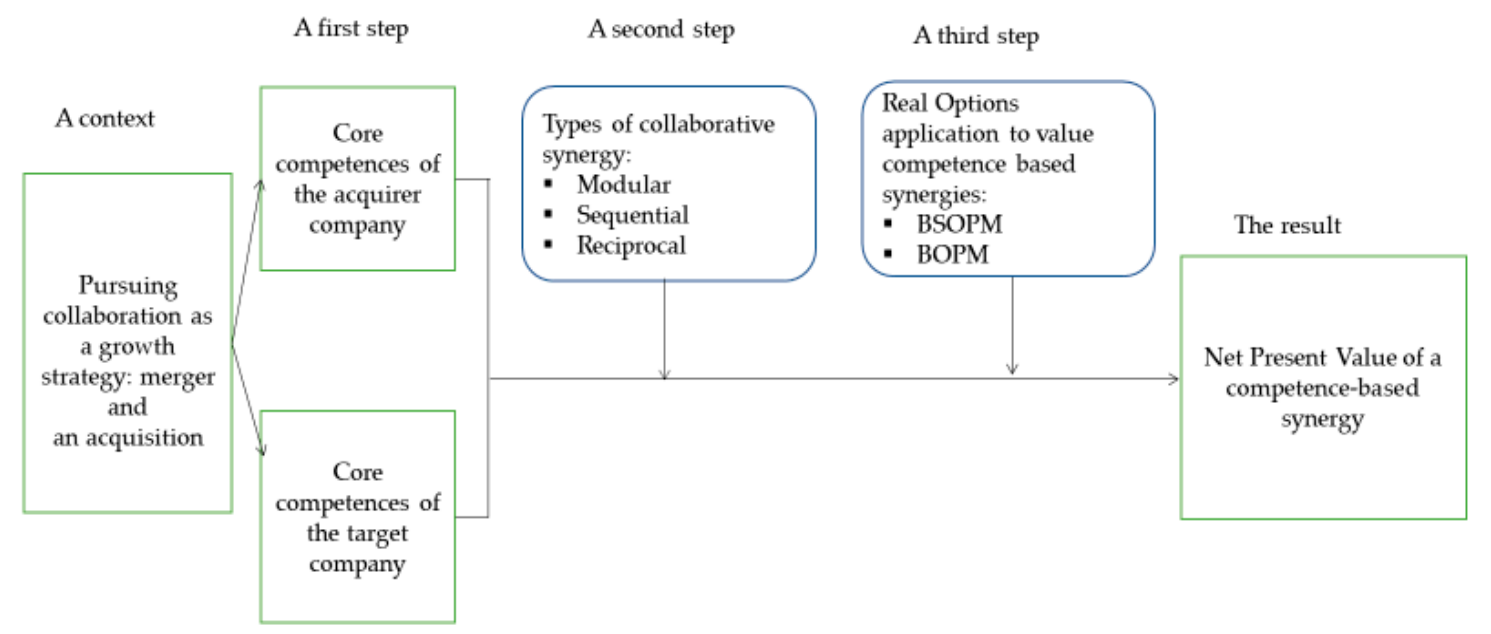

Figure 1. The conceptual model of the current research.

The author asked a research question: how to value strategic synergies in digital transformationbased retail M\&A employing real options? The research question is answered by analyzing an inductive (illustrative) case study that helps an outsider understand critical success factors of competence-based (reciprocal) synergy in the M\&A process and apply a real options valuation technique quantitatively measuring competence-based synergies.

When it comes to the validity of the current case study, validity refers to the extent to which the qualitative research results are accurately represented and the collected data (internal validity) can be generalized or transferred to other contexts or settings (external validity) [32]. The data was collected through primary and secondary sources. For primary data collection, online survey questionnaires were sent to the experts of other grocery retail companies that are active in the business. The survey's questions were related to respondents' experience in M\&A strategies and synergy creation processes. The secondary data analysis added enough information to value a competence-based (reciprocal) synergies quantitatively using real options valuation.

To test the internal and external validity of the proposed conceptual model of the research, it was applied to a recent case of the competence-based M\&A deal in the grocery retail industry-the Ahold-Delhaize merger in 2016.

\section{Data Analysis and Interpretation: Ahold-Delhaize Merger in 2016}

The growth of online grocery shopping is driven in part by the maturation of the digital natives-Millennials and Generation Z. There is a rapid demographic shift among customers, 
and retailers have started relying on technology, namely, on the digital transformation of their business models. In such a challenging landscape, in 2015, Dutch grocer Ahold acquired Belgian food retailer Delhaize for $\$ 28$ billion. The merged entity, known as Ahold Delhaize (AD), became the fourth largest supermarket owner in the USA. The US has been AD's biggest market segment, generating more than $\$ 44$ billion in revenue in 2018. To evaluate how and to what extent the competency-based (reciprocal) synergies had been generated in the Ahold and Delhaize merger process, the core competences exploration and real option valuation are applied.

\subsection{Step 1 is to Identify the Core Competences of Acquirer and Target: Similarities, Compatibilities, and Complementarity}

"The litmus test for a core competence? It's hard for competitors to copy or procure. [5] (p. 1)". To identify the core competences of both companies, an application of the VRIO framework stands for four questions that ask if resources and capabilities are: valuable? rare? costly or/and timely to imitate? efficiently and effectively organized? According to core competences analyses of both companies, they have similar core competencies, but complement each other. Both companies are present in the US market, Ahold USA is mostly active in urban areas, where income is higher, while Delhaize USA's Food Lion chain is mostly active in rural areas, where customers have a lower income. Geographically, Ahold and Delhaize were close and complementary, both in Europe and in the United States. This factor, taking into consideration that there was almost no overlap, would give them a serious competitive advantage by targeting almost the same type of customer (different in the US) while having more resources to tackle the competition.

In terms of strategy, they have a similar business model that adapts to every country they are entering. Meaning that instead of putting their brand on every supermarket, they are buying local retailers to be as close as possible to the local consumer. Their strategies, history, and culture are comparable; they both started as a family business, grew in their country, and were leading the sector for the last decades. Digitalization with e-commerce is having a strong effect on retail's actors.

Before the merger, Delhaize had a modest click-and-collect effort underway at Hannaford. Their CEO from Delhaize America, Kevin Holt, identified e-commerce as a priority for its brands but didn't elaborate on a solution. On the contrary, Ahold had a mature and well-developed e-commerce undertaking in the U.S. and Europe. The company was capable of both click-and-collects thanks to Bol.com subsidiaries. Two growth areas were coming after the merger, convenience retail and online. Ahold has a fully automated e-fulfillment center in New Jersey, designed to quickly, efficiently, and cheaply pick and send online orders.

Delhaize could benefit from it and on the other hand, Ahold could take advantage of Delhaize's competences in convenience retail [38]. An example of innovation, the company is creating automated checkout, self-scanning technology, and digital price labeling on the shelf. Stop \& Shop stores in Windsor, Connecticut, are testing an automated micro-fulfillment center with "Take-off Technologies" that will rely on Robot Pickers to assemble orders. It is a process that speeds up picking and packing and also saves money [38-40].

After the merger, the group said that "Ahold-Delhaize will speed up innovation thanks to its joint expertise to increase customer value and choice in its stores and online" [38] (p. 1). They are now increasing their technological presence through Peapod, robotics, and data analytics; and further personalizing the shopping experience (bid data analytics) in each region they operate.

Moreover, according to Rabobank, both retailers can cut considerable costs. They will use their negotiation power in obtaining lower prices and longer credit terms from the suppliers. What's more, Ahold Delhaize had other options to cut costs thanks to increased synergy: IT, discounts and marketing, logistics, and its online branch [38]. An integration of Ahold and Delhaize's idiosyncratic resources and dynamic capabilities, namely, core competences, would result in gaining competence-based synergies and sustaining their advantage on the grocery market. 
According to Sue Borra, chief health and wellness officer for the Food Marketing Institute (FMI), today's consumers are seeking out products that deliver key health-and-wellness attributes for well-being [41]. "All the trends point to the fact that Alhod Dekhaize that embraces health and wellness as core competences within their brands will be successful in the future [41] (p. 1)".

\subsection{Step 2 is to Assess the Prerequisites of Competence-Based Synergy in the Acquisition Process}

Having assessed the potential of competence-based synergy of the merger of Ahold Delhaize, it became evident that similarities, compatibilities, and complementarity of core competences of Ahold Delhaize helped to develop their further growth. After the merger, the group could benefit from the core competencies of each other. Thanks to the merger, they have gained even more geographic presence in Europe and especially in the USA.

The group has more negotiation power towards suppliers and could increase their margins. Moreover, Ahold Delhaize could penetrate different customer segments in the retail segment that also help the organization to diversify revenue streams. The survey results $(n=180)$ justified success factors of reciprocal synergies as follows: investing in a digital transformation, an extension of product lines, geographical diversification to expand their product portfolio, and effective communication plan between M\&A deal team. Thus, according to the survey, Ahold Delhaize core competences complement each other thanks to digital platform and e-commerce, e-fulfillment centers, broad geographic market coverage, and extended product portfolio.

To predict the type of strategic synergies, the author applied the framework of Dyer et al. The author has adopted the contextual positioning method [42] by using primary and secondary data of an inductive case study and relevant documents as extant data in grounded theory research. Having codified primary and secondary data, the author classified the research results according to the five factors of Dyer's framework. According to the contextual analysis, all five factors suggest that merger and acquisition is the most optimal option to generate synergies as shown in Table 1 . Therefore, thanks to reciprocal competence-based synergy, Ahold Delhaize merger is demonstrating strong acquisition-based dynamic capabilities by sensing global market demand on the digital transformation of grocery retail, seizing opportunities through the merger of the companies with core competencies which complement each other, and transforming their global value chain by increasing their geographical reach of operations.

Table 1. Choosing the type of collaborative strategies and the type of competence-based synergy (Dyer et al. framework), Ahold and Delhaize deal.

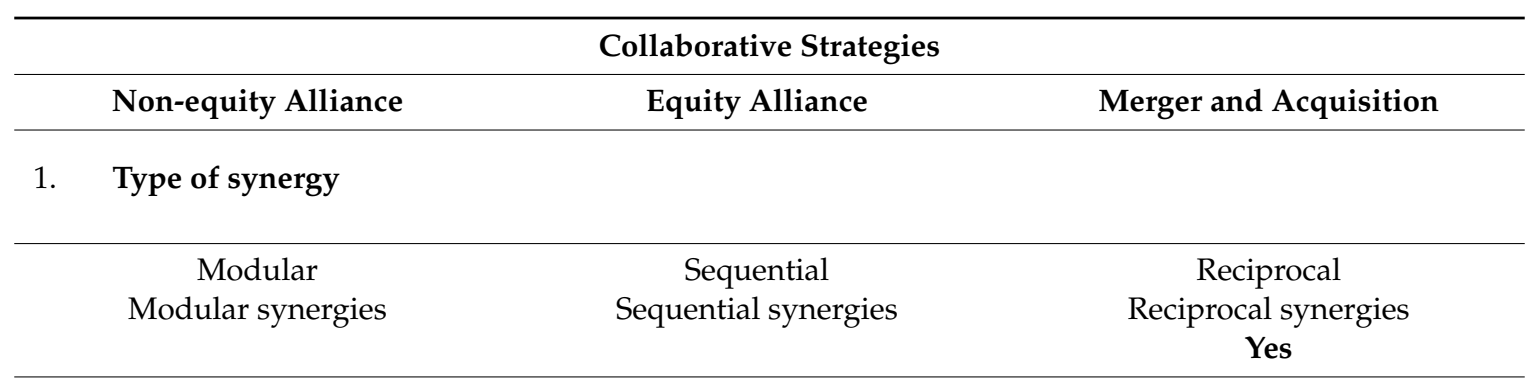

2. Nature of resources (relative value of soft to hard resources)

\begin{tabular}{ccc}
\hline Low & High & Low/Medium \\
$\begin{array}{c}\text { Creating synergy is saddled with } \\
\text { extensive redundant resources }\end{array}$ & $\begin{array}{c}\text { Creating synergy with mostly soft } \\
\text { resources }\end{array}$ & $\begin{array}{c}\text { Creating synergy with mostly } \\
\text { hard resources } \\
\text { Yes }\end{array}$ \\
\hline
\end{tabular}


Table 1. Cont.

\begin{tabular}{ccc}
\hline \multicolumn{3}{c}{ Collaborative Strategies } \\
\hline Non-equity Alliance & Equity Alliance & Merger and Acquisition \\
\hline 3. The extent of redundant resources & & \\
\hline $\begin{array}{c}\text { Low } \\
\text { Modular or sequential synergy } \\
\text { using hard assets }\end{array}$ & $\begin{array}{c}\text { Medium } \\
\text { Sequential synergy using soft } \\
\text { assets }\end{array}$ & $\begin{array}{c}\text { High } \\
\text { Reciprocal synergy using a large } \\
\text { number of redundant resources } \\
\text { Yes }\end{array}$ \\
\hline
\end{tabular}

4. The degree of market uncertainty

\begin{tabular}{ccc}
\hline Low & High & Low/Medium \\
$\begin{array}{c}\text { Collaboration's synergies are } \\
\text { highly uncertain }\end{array}$ & $\begin{array}{c}\text { Collaboration's synergies are } \\
\text { moderately uncertain }\end{array}$ & $\begin{array}{c}\text { Collaboration's synergies are } \\
\text { certain } \\
\end{array}$ \\
& Yes \\
\hline
\end{tabular}

5. Level of competition (degree of competition for resources and users)

\begin{tabular}{ccc}
\hline $\begin{array}{c}\text { Low } \\
\text { No rivals for potential partners }\end{array}$ & $\begin{array}{c}\text { Medium } \\
\text { Some rivals for potential partners }\end{array}$ & $\begin{array}{c}\text { High } \\
\text { Many rivals for potential partners } \\
\text { Yes }\end{array}$ \\
\hline 0 & Total & 5 \\
\hline
\end{tabular}

4.3. Step 3 is to Measure Competence-Based Synergies with a Real Options Valuation Due to the Acquisition Process

Ahold Delhaize has almost reached its target to deliver gross synergies of $€ 750$ million in 2019, resulting in $€ 500$ million net synergies from the integration of the two companies. The increase is mainly driven by the buying activities across all parts of the group [43].

To measure competence-based (reciprocal) synergies as a real option of managerial flexibility in a merger, the Black-Scholes option pricing model and Binominal Lattice or Binominal Option pricing model were applied accordingly. The following data as input variables have been used in valuation. The cumulated market capitalization of target and acquirer before the announcement (So) is a sum of the market capitalization of both separate companies. The market capitalization of Ahold was $€ 15.8$ bn; the market capitalization of Delhaize was $€ 9.1$ bn [44] (p. 12). Thereby, the cumulated market capitalization of the separated entities before the merger (So) equals $€ 24.9 \mathrm{bn}$.

The exercise price (E) is the combined hypothetical future market value after one year without a merger. The hypothetical future market value of the separated entities (target and acquirer) after one year has been calculated using EV/EBITDA (Enterprise Value/Earnings before Interest, Taxes, Depreciation, and Amortization) multiples. Having used Ahold EBITDA \$2622 M [44] or €2146 M [44] (p. 19) in 2015, and EV/EBITDA multiple 7.5 [45] (p. 11), the hypothetical future market value of Ahold without the merger has been estimated as $€ 16.1 \mathrm{bn}$.

Having used Delhaize EBITDA \$1538 M [44] or €1339 M [45] (p. 11) in 2015, and EV/EBITDA multiple 7.0 [45] (p. 11), the hypothetical future market value of Delhaize has been estimated as $€ 9.4 \mathrm{bn}$. Therefore, the cumulated hypothetical future market value of target and acquirer after one-year equals (E) €25.5 bn.

The risk-free rate of return (rf) in 2015 has been defined as Long-Term Government Bond Yields (10-years) for the Netherlands which was $-0.20 \%$ [46]. Thus, the risk-free rate of return (rf) in 2015 was $-0.20 \%$. Expected volatility $(\sigma)$ has been determined based on historical volatilities for three years. 
Following the United States Securities and Exchange Commission (SEC) reports, annual volatility $(\sigma)$ of the Ahold Delhaize group in 2016 was assumed as 22.2\% [30], ([47], F-118).

According to Ahold Delhaize group data [45] (p. 7), the merger was expected to be accretive to earnings in the first full year after completion, with anticipated run-rate synergies of $€ 500$ million per annum to be fully realized in the third year after completion. Cost synergies were expected to be achieved by eliminating duplication, achieving best-of-both efficiencies, and leveraging the scale of the combined company. Sources of synergies over three years would be derived for 50 to 60 percent from branded and non-branded sourcing, 15 to 20 percent from indirect sourcing, and the remaining 25 to 30 percent from general, administrative, and other sources savings.

Therefore, time to expiration in years (T) equals 3 years [45] (p. 7) with five time steps (one step is about 7 months) for the Binominal Option pricing model. The option premium as a competence-based synergies result has been calculated using an Excel spreadsheet. Results are given in Tables 2-5 as follows.

Table 2. Black Scholes option pricing model (Ahold Delhaize merger, in $€ \mathrm{M}$ ). Abbreviations: So, share price; E, exercise price; T, duration; AD, Ahold Delhaize.

\begin{tabular}{cc}
\hline \multicolumn{2}{c}{ Real Options Valuation Black-Scholes } \\
\hline The cumulated market value of target and acquirer before the announcement $(\mathrm{So})$ & $24,900.00$ \\
Hypothetical future market of the separated entities forecast before the merger $(\mathrm{E})$ & $25,500.00$ \\
The risk-free rate of return $(\mathrm{r})$ in 2015 & $-0.20 \%$ \\
Time to expiration in years $(\mathrm{T})$ & 3 \\
The volatility of future share price AD $(\sigma)$ in 2015 & $22.20 \%$ \\
$\mathrm{~d} 1$ & 0.115 \\
$\mathrm{~d} 2$ & -0.270 \\
Value of the call option = Synergy $(C)$ & $\mathbf{3 4 8 8} \mathbf{E}$ \\
\hline
\end{tabular}

Table 3. Binominal option pricing model: a lattice of the underline values of Ahold Delhaize merger (in $€ \mathrm{M})$.

\begin{tabular}{|c|c|c|c|c|c|}
\hline Stepping Time: $\delta t 0$ & $\delta t 1$ & $\delta t 2$ & $\delta t 3$ & $\delta t 4$ & $\delta t 5$ \\
\hline $\begin{array}{l}\text { Underline value: } \\
24,900.00 €\end{array}$ & $\begin{array}{l}29,572.01 € \\
20,966.11 €\end{array}$ & $\begin{array}{l}35,120.63 € \\
24,900.00 € \\
17,653.73 €\end{array}$ & $\begin{array}{l}41,710.35 € \\
29,572.01 € \\
20,966.11 € \\
14,864.66 €\end{array}$ & $\begin{array}{l}49,536.49 € \\
35,120.63 € \\
24,900.00 € \\
17,653.73 € \\
12,516.23 €\end{array}$ & $\begin{array}{l}58,831.07 € \\
41,710.35 € \\
29,572.01 € \\
20,966.11 € \\
14,864.66 € \\
10,538.82 €\end{array}$ \\
\hline
\end{tabular}

Table 4. Recombining binomial lattice parameters (Ahold Delhaize merger).

\begin{tabular}{cc}
\hline Real Options Binomial Option Pricing Model \\
\hline time increment (years) & 0.60 \\
up factor $(\mathrm{u})$ & 1.188 \\
down factor $(\mathrm{d})$ & 0.842 \\
risk-neutral probability $(\mathrm{p})$ & 0.454 \\
\hline
\end{tabular}


Table 5. Binominal Option pricing model. Real options lattice: a value of synergies of Ahold Delhaize merger (in $€ M$ ).

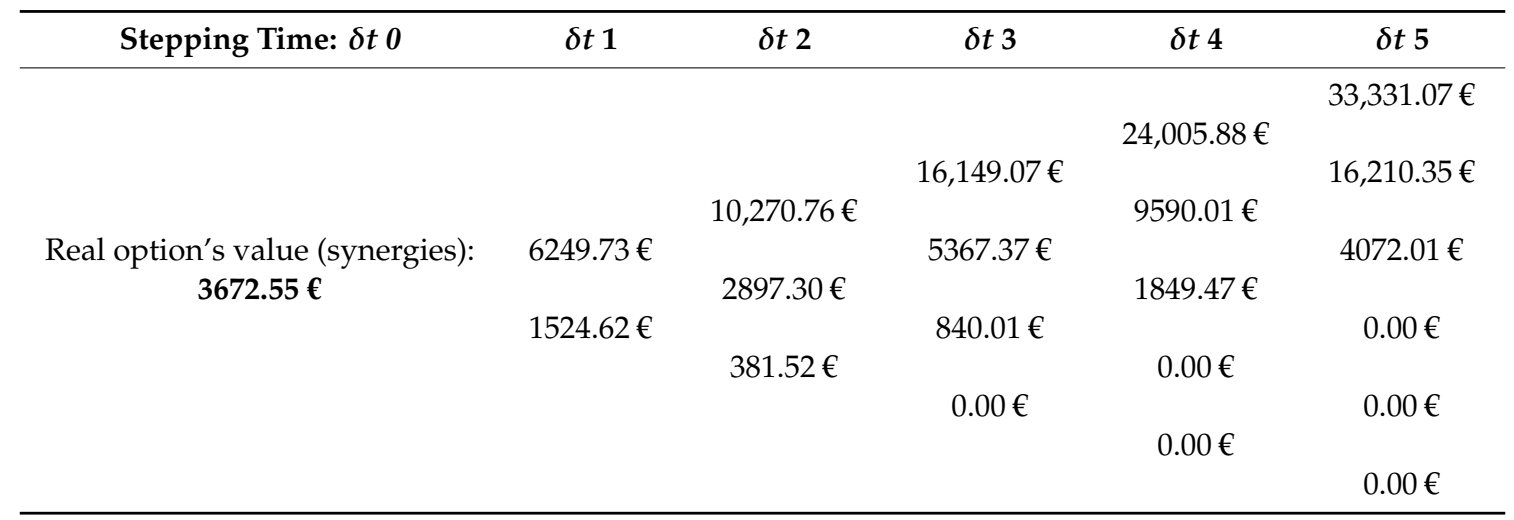

According to the Black-Sholes Option pricing model (BSOPM), the value of the real option (call option value as synergies value) equals $€ 3.5 \mathrm{bn}$. According to the Binominal Option pricing model (BOPM) equals $€ 3.7 \mathrm{bn}$. When it comes to differences in values given by BSOPM and BOPM, the author assumes that it appeared due to relatively low numbers of time-steps increments producing just five possible investment outcomes in BOPM. Moreover, BOPM provides a straightforward understanding and visualizes how M\&A uncertainty represented by volatility influences option value during its lifetime.

According to BSOPM and BOPM, the computation of the value of competence-based synergies evidence that the AD company had added market value of about $€ 3.5-3.7$ billion, let us say an average added value equal to $€ 3.6 \mathrm{bn}$. Therefore, the expected market value of merging the Ahold Delhaize company is the cumulated future market value of target and acquirer after the announcement (So) - $€ 25.5$ bn plus synergies of $€ 3.6$ bn equals future market value of $€ 29.1$ bn. Having known an estimated EBITDA $€ 4305 \mathrm{M}$ as actual data of Ahold Delhaize for 2018, and a forecast for 2019 EV/EBITDA multiple as 6.75 [48], the theoretical market value (capitalization) of Ahold Delhaize today is $€ 29.1 \mathrm{bn}$.

The value justifies the synergies' estimated results, evidenced by how within the last three years, Ahold Delhaize maximized market value according to forecasted synergies (real option value), and reciprocal synergies are fully realized. These results prove the validity of the current research and propositions developed in the paper. It is a convinced example of a digital transformation-based grocery retail M\&A. There are many other options for a newly formed company to cut costs thanks to increased competence-based synergies: IT, discounts and marketing, logistics, and not in the least in its online branch. Ahold is undoubtedly one of the world's best when it comes to building an efficient online supply chain, a necessity especially because of the increased competition in the United States from non-traditional retailers like Instacart and Amazon [38].

To conclude, the application of the real options helps to estimate a synergy in terms of market value-added, not only in terms of cost-saving and/or revenues rising. The valuation of competence-based synergies by real options gives practitioners a clearer strategic observation of the reciprocal synergism of the M\&A deal.

\section{Discussion}

The answers to the research question are given empirically. Having analyzed the successful merger of Ahold Delhaize in 2016 and developing a new conceptual research model given in Figure 1, the paper made several theoretical and managerial contributions. An illustrative case study shows that the model fulfills its purpose and helps in pre-acquisition analysis on competence-based synergies in the M\&A processes, it is the paper's main contribution to theoretical and practical issues of global M\&A issues. Having assessed the merger of Ahold Delhaize in terms of the potential of competence-based 
synergy, the author has identified several core competences as antecedents of the competence-based synergies, and justified that the merger is an optimal collaborative strategy for the Ahold Delhaize deal as shown in Table 1.

The underpinnings of the competence-based synergies are as follows: a digital transformation challenges and Ahold digital transformation advantages; companies' geographical complementarity onto the markets; their desire to learn, to absorb new competences to digitally innovate, and transform companies; the three-year plan (2016-2018) on the integration of companies' resources with expected synergies of about $€ 750$ million in 2019 [43], processes, and e-commerce platforms, clear organizational arrangements and communication plans of integration; and the last factor impacting to competence-based synergies creation is an effective cultural transformation of both companies.

Moreover, the current research points out that the real option application provides an adequate practical approach for synergy valuation with an application of BSOPM and BOPL techniques as shown in Tables 2-5. Ideally, the proposed application of real options valuation should be used before merger and acquisition strategies, not after the acquisition as in the current research.

Proposing a research methodology, this paper highlighted the added value from the conceptual model of the research (Figure 1), which could help to improve strategic decisions in the M\&A process. The application of real options valuation technique demonstrates quantitatively overall synergetic effects pre-mergers, during-merger, and post-merger. This is the first theoretical contribution. Having used a real option to value managerial synergy in real case studies, the paper contributes to the real options theory in strategic management. This is the second theoretical contribution.

Regarding managerial contribution, the proposed approach to value M\&A synergy (Figure 1) can be used by firms before an M\&A deal in the due diligence process. Acquirers need to integrate core competences of targets to create a market value-added that can be measured using real options application. Figure 2 illustrates the likely relationships among the main constructs presented in the paper, with core competences shown as an antecedent of managerial synergies.

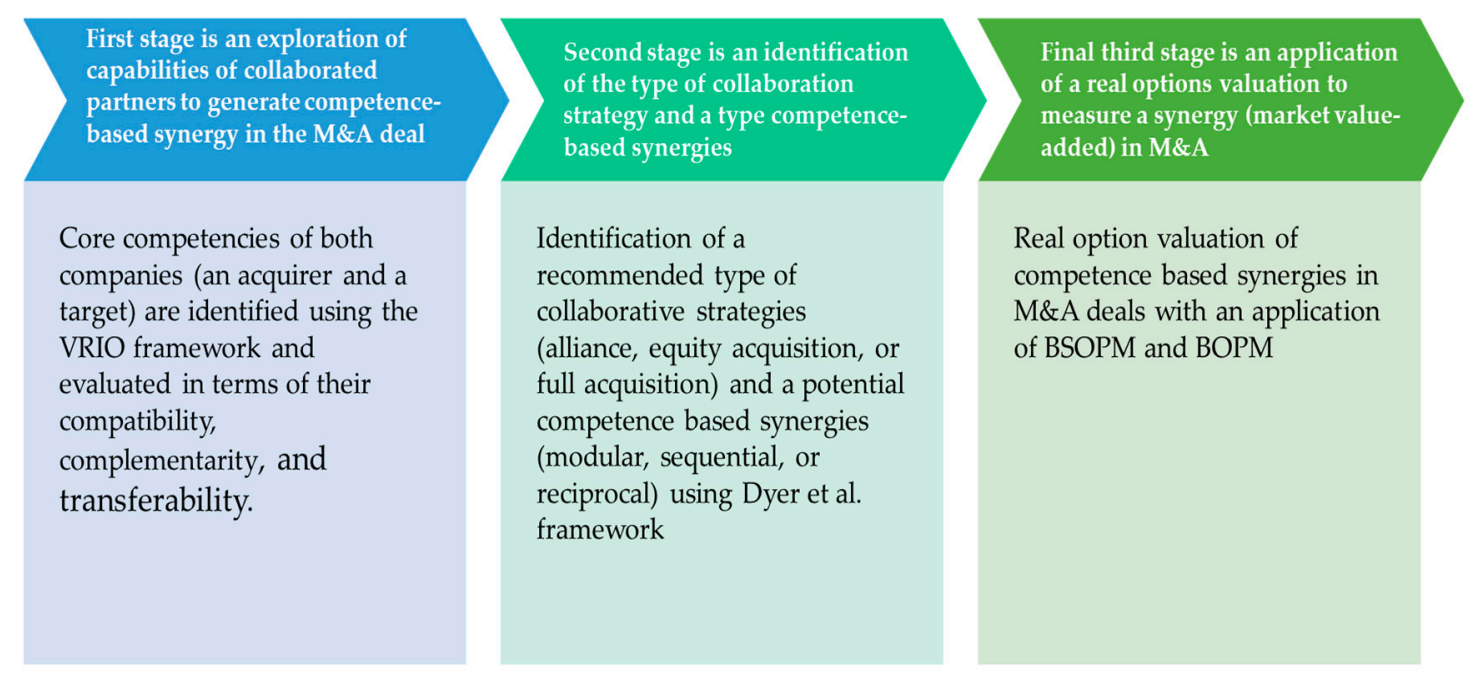

Figure 2. The relationships among the main constructs of the research.

\section{Conclusions, Limitation, and Future Work}

"The adoption of digital technologies based on ICT is considered to be an important tool for the socio-economic growth of the country" [49] (p. 2). The collaborative approach to technology and innovation has become very important not only for research and technology organizations [50] (p. 7), but for the global grocery retail industry as well. It turned out, that the digitalization challenge in the grocery business, changing customer demand, and the fierce competition in the grocery market was the main rationales behind the merge of Ahold Delhaize. The rationale behind the Ahold Delhaize 
merger in 2016 was to face competition in the U.S. market by joining their market shares and reinforce them by digitally transforming their purchasing power and setting up the e-fulfillment centers.

Synergy is the magic ingredient that allows acquirers to pay billions of dollars in premiums in mergers and acquisitions for a combination of different "functional strengths" [51] or, more specifically, for a new combination of different tacit and codified knowledge, and core competences. Thereby, the current research justifies the argument that "enterprise digitalization is a way for companies to make their processes more efficient, to enhance their marketing strategies, and improve their competitive moat within the global competitive landscape" [52] (p. 1). The AD company unleashes the potential benefits of Artificial Intelligence (AI), robotics, and an integrated transportation management system to leverage its scale, optimally use the local brands to serve customers with varieties of food at an affordable price, and therefore to sustain competitive advantage on the US market [53].

However, there are several limitations to the application of the current research framework. The evaluation of strategies, such as non-equity alliance, equity alliance, or acquisition, is made based on the assumption that all five factors, specifically, the type of synergy, the nature of resources, the extent of redundant resources, the degree of market uncertainty, and the level of competition, have the same weight of significance. The weighting of the five factors of the Dyer et al. framework, particularly for the global grocery industry, is promising future research work. More interviews with industry practitioners and their expert judgments are needed.

Finally, new competences creation in M\&As, as well as knowledge leveraging and pursuing business model transformations, are important acquisition-based dynamic capabilities that could be the subject of future research papers.

Author Contributions: Conceptualization, A.Č.; methodology, A.Č.; software, A.Č.; validation, A.Č., formal analysis, A.Č.; investigation, A.Č. and V.B.; resources, A.Č.; data curation, A.Č.; writing-original draft preparation, A.Č.; writing一review and editing, A.Č.; visualization, A.Č.; supervision, A.Č.; project administration, A.Č.; funding acquisition, A.Č. All authors have read and agreed to the published version of the manuscript.

Funding: This research received no external funding.

Acknowledgments: The paper support from RISEBA University of Applied Sciences in Business, Arts, and Technology is gratefully acknowledged. Assistance in data collection by Victoire Baratoux (V.B.) is gratefully acknowledged.

Conflicts of Interest: The authors declare no conflict of interest.

\section{References}

1. Prahalad, C.K.; Hamel, G. The Core Competence of the Organization; Harvard Business Review: Brighton, MA, USA, 1990; pp. 79-93.

2. Jahanshahi, A.A.; Nawaser, K. Is real option reasoning a cause or consequence of dynamic capability? Strateg. Chang. 2018, 27, 395-402. [CrossRef]

3. Teece, D.J.; Pisano, G.; Shuen, A. Dynamic capabilities and strategic management. Strateg. Manag. J. 1997, 18, 509-533. [CrossRef]

4. Trigeorgis, L.; Reuer, J.J. Real options theory in strategic management. Strateg. Manag. J. 2017, 38, 42-63. [CrossRef]

5. Bain Company. Core Competencies. Available online: https://www.bain.com/insights/management-tools-c ore-competencies/ (accessed on 28 February 2020).

6. Barney, J.B. Gaining and Sustaining Competitive Advantage; Addison Wesley: Boston, MA, USA, 1996.

7. Fleming, L. Recombinant Uncertainty in Technological Search, Management Science. 2001, Volume 47. Available online: https://pubsonline.informs.org/doi/10.1287/mnsc.47.1.117.10671 (accessed on 20 January 2020).

8. Hawk, A.; Pacheco de Almeida, G. Time Compression (Dis) Economies: An Empirical Analysis. Strateg. Manag. J. 2018, 39, 2489-2516. [CrossRef]

9. Bowman, E.H.; Moskowitz, G.T. Real Options Analysis and Strategic Decision Making. Organ. Sci. 2001, 12, 772-777. [CrossRef] 
10. Johnson, G. Managing strategic change-Strategy, culture, and action. Long Range Plan. 1992, 25, $28-36$. [CrossRef]

11. Rozen-Bakher, Z. Could the pre-M\&A performances predict integration risk in cross-border M\&As? Int. J. Organ. Anal. 2018, 26, 652-668.

12. Homburg, C.; Bucerius, M. Is the speed of integration a success factor of mergers and acquisitions? An analysis of the role of internal and external relatedness. Strateg. Manag. J. 2006, 27, 347-367. [CrossRef]

13. King, D.R.; Slotegraaf, R.J.; Kesner, I. Performance implications of firm resource interactions in the acquisition of the R\&D-intensive firm. Organ. Sci. 2008, 19, 327-340.

14. Meyer, C.B.; Altenborg, E. Incompatible strategies in international mergers: The failed merger between Telia and Telenor. J. Int. Bus. Stud. 2008, 39, 508-525. [CrossRef]

15. Cartwright, S.; Schoenberg, R. Thirty years of mergers and acquisitions research: Recent advances and future opportunities. Br. J. Manag. 2006, 17, S1-S5. [CrossRef]

16. Lodorfos, G.; Boateng, A. The role of culture in the merger and acquisition process: Evidence from the European chemical industry. Manag. Decis. 2006, 44, 1405-1421. [CrossRef]

17. Nguyen, H.; Kleiner, B.H. The effective management of mergers. Leadersh. Organ. Dev. J. 2003, 24, 447-454. [CrossRef]

18. Haspeslagh, J.D.B. Managing Acquisitions; The Free Press: New York, NY, USA, 1991.

19. Stahl, G.K.; Voigt, A. Do cultural differences matter in mergers and acquisitions? A tentative model and examination. Organ. Sci. 2008, 19, 160-176. [CrossRef]

20. Cording, M.; Christmann, P.; King, D. Reducing causal ambiguity in acquisition integration: Intermediate goals as mediators of integration decisions and acquisition performance. Acad. Manag. J. 2008, 51, 744-767. [CrossRef]

21. Karim, S. Modularity in organizational structure: The reconfiguration of internally developed and acquired business units. Strateg. Manag. J. 2006, 27, 799-823. [CrossRef]

22. Pablo, A.L. Determinants of acquisition integration level: A decision-making perspective. Acad. Manag. J. 1994, 37, 803-836.

23. Angwin, D. Speed in M\&A integration: The first 100 days. Eur. Manag. J. 2004, 22, 418-430.

24. Bauer, F.; Matzler, K. Antecedents on M\&A success: The role of strategic complementary, cultural fit, and degree and speed on integration. Strateg. Manag. J. 2014, 35, 269-291.

25. Dyer, J.H.; Kale, P.; Singh, H. When to Ally and When to Acquire. Harv. Bus. Rev. 2004, 82, 108-115.

26. Rabier, M.R. Acquisition Motives and the Distribution of Acquisition Performance. Strateg. Manag. J. 2017, 38, 2666-2681. [CrossRef]

27. Loukianova, A.; Nikulin, E.; Vedernikov, A. Valuing synergies in strategic mergers and acquisitions using the real options approach. Invest. Manag. Financ. Innov. 2017, 14, 236-247. [CrossRef]

28. Bruner, R. Applied Mergers and Applications; John Wiley \& Sons: New York, NY, USA, 2004.

29. Dunis, C.L.; Klein, T. Analyzing Mergers and Acquisitions in European Financial Services: An Application of Real Options. Eur. J. Financ. 2005, 11, 339-355. [CrossRef]

30. NYU Stern, Koninklijke Ahold Delhaize NV APARCH Volatility Analysis. Available online: https://vlab.ste rn.nyu.edu/analysis/VOL.AD:NA-R.APARCH (accessed on 30 September 2019).

31. Yin, R.K. Case Study Research: Design and Methods; Sage: Newbury Park, CA, USA, 1984.

32. Sekaran, U.; Bougie, R. Research Methods for Business: A Skill Building Approach; Wiley: Hoboken, NJ, USA, 2018.

33. Yin, R.K. Case Study Research: Design and Methods, Applied Social Research Series, 4th ed.; Sage Publications: Newcastle, UK, 2009; Volume 5.

34. Johnston, M.P. Secondary Data Analysis: A Method of which the Time Has Come. Qual. Quant. Methods Libr. 2014, 3, 619-626.

35. Smith, E. Using Secondary Data in Educational and Social Research; McGraw-Hill Education: New York, NY, USA, 2008.

36. Andrews, L.; Higgins, A.; Andrews, M.W.; Lalor, J.G. Classic grounded theory to analyze secondary data: Reality and reflections. Grounded Theory Rev. 2012, 11, 12-26.

37. Eisenhardt, K.M.; Graebner, M.E. Theory building from cases: Opportunities and challenges. Acad. Manag. J. 2007, 50, 25-32. [CrossRef] 
38. Retail Detail. Analysis: Ahold-Delhaize Merger is a Necessity, Even for Ahold. Available online: https: //www.retaildetail.eu/en/news/mode/analysis-ahold-delhaize-merger-necessity-even-ahold (accessed on 30 September 2019).

39. Thomasson, E.; Fares, M. Reuters 7 November 2018. Available online: https://www.businessinsider.com/r-ah old-ups-stakes-in-us-grocery-war-with-mini-robot-supermarkets-2018-11 (accessed on 21 January 2020).

40. Grocery Dive. Can Stop \& Shop 'Test and Learn' Its Way to a Turnaround? Available online: https: //www.grocerydive.com/news/can-stop-shop-test-and-learn-its-way-to-a-turnaround/539142/ (accessed on 21 February 2020).

41. Redman, R. Ahold Delhaize USA Eyes 'Cleaner' Private Brands. Available online: https://www.supermarke tnews.com/private-label/ahold-delhaize-usa-eyes-cleaner-private-brands (accessed on 28 February 2020).

42. Ralph, N.; Birks, M.; Chapman, Y. Contextual Positioning: Using Documents as Extant Data in Grounded Theory Research; SAGE Open: Newcastle, UK, 2015; pp. 1-7.

43. Ahold Delhaize. Annual Report 2018. Available online: https://www.aholddelhaize.com/media/8833/ahold -delhaize-2018-annual-report.pdf (accessed on 21 February 2020).

44. Ahold Delhaize Group. Brussel June 24. Available online: https://www.aholddelhaize.com/media/2154/aho ld_delhaize_presentation_final_3.pdf (accessed on 21 January 2020).

45. Board Report Ahold. Available online: https://www.aholddelhaize.com/media/2156/board_report_ahold.pdf (accessed on 21 January 2020).

46. Guru Focus. Available online: https://www.gurufocus.com/economic_indicators/130/10year-treasury-consta nt-maturity-rate (accessed on 21 January 2020).

47. United States Securities and Exchange Commission (SEC) Reports. Available online: https://www.sec.gov/ Archives/edgar/data/869425/000119312517095046/d358563d20f.htm (accessed on 21 January 2020).

48. MarketScreener. Ahold Delhaize, N.V. Available online: https://www.marketscreener.com/AHOLD-DELHA IZE-N-V-29752127/financials/ (accessed on 21 January 2020).

49. Park, H.J.; Choi, S.O. Digital Innovation Adoption and it's Economic Impact Focused on Path Analysis at National Level. J. Open Innov. Technol. Mark. Complex. 2019, 5, 56. [CrossRef]

50. Uribe-Echeberria, R.; Igartua, J.I.; Lizarralde, R. Implementing Open Innovation in Research and Technology Organizations: Approaches and Impact. J. Open Innov. Technol. Mark. Complex 2019, 5, 91. [CrossRef]

51. Damodaran, A. The Value of Synergy, New York University-Stern School of Business. p. 47. Available online: https://papers.ssrn.com/sol3/papers.cfm?abstract_id=841486 (accessed on 21 January 2020).

52. Eremina, Y.; Lace, N.; Bistrova, J. Digital Maturity and Corporate Performance: The Case of the Baltic States. J. Open Innov. Technol. Mark. Complex 2019, 5, 54. [CrossRef]

53. Majumdar, S.; Shah, R. Ahold Delhazie AI Driven Supply Chain Initiatives. Amity Res. Cent. Bangalore 2019, $319,1-5$.

(C) 2020 by the author. Licensee MDPI, Basel, Switzerland. This article is an open access article distributed under the terms and conditions of the Creative Commons Attribution (CC BY) license (http://creativecommons.org/licenses/by/4.0/). 